\title{
HELIUM POROSITY DEVELOPMENT DURING ANNEALING OF HELIUM-IMPLANTED 18Cr10NiTi STEEL
}

\author{
V.V. Ruzhytskyi, (D.A. Karpov*, A.S. Kalchenko, I.E. Kopanets, B.S. Sungurov, \\ G.D. Tolstolutskaya \\ National Science Center "Kharkov Institute of Physics and Technology" \\ 1, Akademicheskaya Str., Kharkov 61108, Ukraine \\ *E-mail: karpofff@kipt.kharkov.ua
}

Received 4 November 2018, accepted 6 December 2018

\begin{abstract}
The kinetics of helium porosity development during annealing of $18 \mathrm{Cr} 10 \mathrm{NiTi}$ stainless steel irradiated with $20 \mathrm{keV}$ helium ions at room temperature for simultaneous creation of displacement damage at a level of $0.5-5 \mathrm{dpa}$ and a helium concentration of 1-12 at.\%, have been investigated by electron microscopy and thermal desorption spectrometry. The temperature ranges of helium release from steel and their dependence on the irradiation dose are determined. The evolution of 18Cr10NiTi steel microstructure was investigated during post-implantation annealing in the temperature range from $\mathrm{T}_{\text {room }}$ to $1420 \mathrm{~K}$. At a dose of $1 \cdot 10^{20} \mathrm{~m}^{-2}$, helium bubbles were detected only after annealing to a temperature of $890 \mathrm{~K}$, while at a dose of $1 \cdot 10^{21} \mathrm{~m}^{-2}$, bubbles were observed immediately after radiation at $T_{\text {room. }}$. During annealing, the average diameters of the bubbles vary from $\sim 1 \mathrm{~nm}$ at $T_{\text {room }}$ to $10-20 \mathrm{~nm}$ at $\mathrm{T}_{\text {ann }} 1420 \mathrm{~K}$. The mechanisms of bubbles growth either by migration and coalescence, or by Ostwald ripening - dissolution and re-trapping are considered. Since each of these mechanisms corresponds to a certain trend of bubbles size and density dependence on the annealing temperature, the temperature dependences of average diameters and densities of helium bubbles for a dose of $1 \cdot 10^{21} \mathrm{~m}^{-2}$ have been constructed and analyzed. Experimental data are characterized by three temperature ranges: 1 - from 300 to $760 \mathrm{~K}, 2$ - from 760 to $1030 \mathrm{~K}$, and 3 - from 1030 to $1350 \mathrm{~K}$ with clearly differing trends. In the low-temperature region the diameter and density of the bubbles virtually does not change. Their size increases and the density decreases at annealing in the temperature range 760-1030 K. This tendency intensifies in the temperature range of 1030-1420 K. An estimation of activation energy of the processes controlling the mechanism of bubble growth in the temperature range of 1000-1420 K has been done. An obtained value of $\sim 3.7 \mathrm{eV}$ correlates well with the theoretically calculated value of the activation energy of the dissociation process $\left(\mathrm{E}_{\mathrm{He}}{ }^{\mathrm{diss}}\right)$ of the Ostwald ripening mechanism.
\end{abstract}

KEY WORDS: austenitic steel, irradiation, helium, bubbles, thermal desorption, microstructure.

\section{РОЗВИТОК ГЕЛІЕВОЇ ПОРИСТОСТІ ПРИ ВІДПАЛІ ІМПЛАНТОВАНОЮ ГЕЛІЕМ СТАЛІ Х18Н10Т В.В. Ружицький, С.О. Карпов, О.С. Кальченко, І.С. Копанець, Б.С. Сунгуров, Г.Д. Толстолуцька \\ Національний науковий центр «Харківський фізико-технічний інститут» вул. Академічна 1, Харків 61108, Україна}

Кінетика процесів розвитку гелієвої пористості при відпалі нержавіючої сталі Х18Н10Т, опроміненої іонами гелію 3 енергією 20 кеВ при кімнатній температурі для одночасного створення зміщуючих пошкоджень на рівні 0,5-5 зна $\mathrm{i}$ концентрації гелію 1-12 ат.\% досліджена методами електронної мікроскопії та термодесорбційної спектрометрії. Визначено температурні інтервали виходу гелію зі сталі та їх залежність від дози опромінення. Досліджено еволюцію мікроструктури сталі Х18Н10Т в процесі постімплантаційних відпалів в інтервалі температур від Ткімн до 1420 К. При дозі опромінення $1 \cdot 10^{20} \mathrm{M}^{-2}$ гелієві бульбашки були виявлені тільки після відпалу до температури $890 \mathrm{~K}$, при дозі $1 \cdot 10^{21} \mathrm{M}^{-2}$ бульбашки спостерігалися відразу після опромінення при Ткімн. В процесі відпалу середній діаметр бульбашок змінюється від 1 нм при

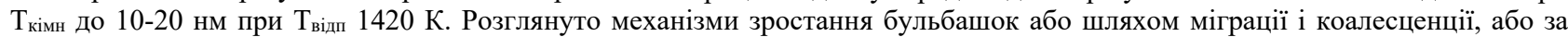
механізмом Оствальда - розчинення і перезахоплення. Оскільки кожному з цих механізмів відповідає певний тренд залежності розмірів і щільності бульбашок від температури відпалу, побудовані і проаналізовані температурні залежності середніх діаметрів і щільності гелієвих бульбашок для дози $1 \cdot 10^{21} \mathrm{M}^{-2}$. Експериментальні дані характеризуються трьома температурними інтервалами: 1 - від 300 до 760 К, 2 - від 760 до 1030 К і 3 - від 1030 до 1350 К з трендами, які явно різняться. У низькотемпературній області діаметр і щільність бульбашок практично не змінюється. При відпалі в області температур від 760 до 1030 К починається зростання їх розмірів і зниження щільності. Ця тенденція посилюється в області температур 1030-1420 К. Виконано оцінку енергії активації процесів, які контролюють механізм росту бульбашок в області температур 1000-1420 К. Отримано значення $\sim 3,7$ еВ, яке добре корелює 3 теоретично розрахованою величиною енергії активації процесу дисоціації ( $\mathrm{E}_{\mathrm{He}}{ }^{\text {diss }}$ ) за механізмом Оствальда.

КЛЮЧОВІ СЛОВА: аустенітна сталь, опромінення, гелій, бульбашки, термодесорбція, мікроструктура

\section{РАЗВИТИЕ ГЕЛИЕВОЙ ПОРИСТОСТИ ПРИ ОТЖИГЕ ИМПЛАНТИРОВАННОЙ ГЕЛИЕМ СТАЛИ Х18Н10Т В.В. Ружицкий, С.А. Карпов, А.С. Кальченко, И.Е. Копанец, Б.С. Сунгуров, Г.Д. Толстолуцкая Национальный научный иентр «Харьковский физико-технический институт»} ул. Академическая 1, Харьков 61108, Украина

Кинетика процессов развития гелиевой пористости при отжиге нержавеющей стали Х18Н10Т, облученной ионами гелия с энергией 20 кэВ при комнатной температуре для одновременного создания смещающих повреждений на уровне $0,5-5$ сна и концентрации гелия $1-12$ ат.\%, исследована методами электронной микроскопии и термодесорбционной спектрометрии. Определены температурные интервалы выхода гелия из стали и их зависимость от дозы облучения. Исследована эволюция микроструктуры стали X18Н10T в процессе постимплантационных отжигов в интервале температур от Ткомн до 1420 К. При 
дозе облучения $1 \cdot 10^{20} \mathrm{M}^{-2}$ гелиевые пузырьки были обнаружены только после отжига до температуры 890 К, при дозе $1 \cdot 10^{21} \mathrm{M}^{-2}$ пузырьки наблюдались сразу после облучения при $\mathrm{T}_{\text {комн. }}$ В процессе отжига средний диаметр пузырьков

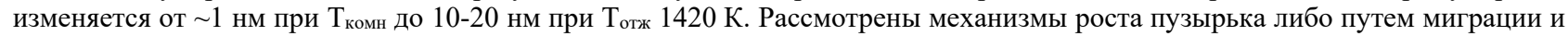
коалесценции пузырьков, либо по механизму Оствальда - растворение и перезахват. Поскольку каждому из этих механизмов соответствует определенный тренд зависимости размеров и плотностей пузырьков от температуры отжига, построены и проанализированы температурные зависимости средних диаметров и плотностей гелиевых пузырьков для дозы $1 \cdot 10^{21} \mathrm{M}^{-2}$. Экспериментальные данные характеризуются тремя температурными интервалами: 1 - от 300 до 760 К, 2 - от 760 до 1030 К и 3 - от 1030 до 1350 К с явно различающимися трендами. В низкотемпературной области диаметр и плотность пузырьков практически не меняется. При отжиге в области температур от 760 до 1030 К начинается рост их размеров и снижение плотности. Эта тенденция нарастает в области температур 1030-1420 К. Выполнена оценка энергии активации процессов, контролирующих механизм роста пузырьков в области температур 1000-1420 К. Получено значение $\sim 3,7$ эВ, которое хорошо коррелирует с теоретически рассчитанной величиной энергии активации процесса диссоциации (Ене $\left.{ }^{\text {diss }}\right)$ по механизму Оствальда.

КЛЮЧЕВЫЕ СЛОВА: аустенитная сталь, облучение, гелий, пузырьки, термодесорбция, микроструктура

Конструкционные материалы ядерных энергетических установок по сравнению с материалами традиционных энергетических установок работают в более сложных условиях. Нейтронное облучение ускоряет процессы ползучести, усиливает временную зависимость прочности, резко снижает пластичность при умеренных $\left(20 \ldots 450^{\circ} \mathrm{C}\right)$, высоких $\left(500 \ldots 800^{\circ} \mathrm{C}\right)$ и особенно сверхвысоких (выше $\left.800^{\circ} \mathrm{C}\right)$ температурах, снижает сопротивление коррозии. Накопление определенной дозы нейтронов вызывает порообразование и радиационное распухание. В результате ядерных реакций в материалах образуются газообразные трансмутанты (гелий, водород), способствующие проявлению гелиевого охрупчивания, водородной хрупкости и газового распухания [1].

Типичные концентрации гелия, по отношению к одному смещению атома матрицы (сна) из его равновесного положения в решетке (Не/сна), составляют $<<1$ для реакторов на быстрых нейтронах, около десятков для реакторов синтеза и сотен для установок ADS (accelerator-driven spallation devices, установки управляемые ускорителем). Атомы гелия практически не растворимы в решетке металлов и, вследствие этого, стремятся объединяться в вакансионно-гелиевые кластеры и пузырьки, которые приводят к деградации эксплуатационных свойств реакторных материалов [2-4].

Большинство исследований влияния гелия на развитие радиационных повреждений выполнено с помощью метода ионной имплантации, что позволило к середине 90-х годов прошлого столетия получить основные представления о поведении гелия в твердом теле. Были определены энергии образования гелия в междоузельном и замещающем положениях, энергии связи с вакансией, энергии активации для междоузельной миграции гелия, энергии перемещения гелия из замещающего положении в ближайшую вакансию [3].

Исследования проводили как на чистых металлах, так и сплавах. В частности, достаточно широко изучено поведение гелия в аустенитных нержавеющих сталях. Аустенитные коррозионно-стойкие стали - это стали, обычно легированные хромом и никелем (марганцем), которые после охлаждения до комнатной температуры имеют аустенитную структуру, низкий предел текучести, умеренную прочность, высокую пластичность и хорошую коррозионную стойкость в окислительных средах.

Ранее [5] методами наноиндентирования и электронной микроскопии исследованы упрочнение аустенитной нержавеющей стали SS316 и эволюция ее микроструктуры после облучения тяжелыми ионами с энергией 1,4 МэВ в интервале смещающих доз 0-30 сна при температурах 300 и 900 К и концентрациях гелия от 0,5 до 5 ат.\%. Установлено, что радиационное упрочнение стали является функцией дозы облучения, достигает насыщения при флюенсах около 1 сна и составляет 2.0 0.3 ГПа. Установлена корреляция между эволюцией микроструктуры и изменением твердости облученного слоя стали. Показано, что закрепление дислокаций, приводящее к упрочнению стали SS316, происходит на дислокационных петлях междоузельного типа диаметром до 15 нм. Гелий усиливает упрочнение на 20-30\% при концентрациях более 1 ат.\% [5]. Для определения роли гелия в упрочнении необходимы микроструктурные исследования развития гелиевой пористости как в области низкотемпературного, так и высокотемпературного упрочнения.

В [6] отмечено, что исследования гелиевой пористости выполнялись, в основном, в двух направлениях: (i) облучение при повышенной температуре и (ii) облучение при низкой температуре (обычно комнатной) с последующим отжигом. В экспериментах первого типа непрерывное введение газа способствует стабилизации пузырьков, зарождающихся уже на ранних стадиях облучения, и, таким образом, после прекращения облучения материал сохраняет информацию о процессе зародышеобразования. В случае облучения при низкой температуре с последующим отжигом судить о начальном состоянии кластеров Не -V и процессе зарождения пузырьков достаточно сложно. Однако такие эксперименты позволяют контролировать процессы термоактивированного выделения газа, исследовать детали кинетики роста пузырьков, и могут предоставить информацию об их миграции, коалесценции и аннигиляции.

Целью настоящей работы было исследование кинетики процессов в системе «металл-гелий» при отжиге нержавеющей стали Х18Н10Т, облученной при комнатной температуре ионами гелия с энергией 20 кэВ для одновременного создания смещающих повреждений на уровне 0,5 - 5 сна и концентрации гелия 1 - 12 ат.\%. 


\section{МАТЕРИАЛЫ И ЭКСПЕРИМЕНТАЛЬНЫЕ МЕТОДИКИ}

Для исследований использовали образцы размерами $27 \times 7 \times 0,1$ мм из стали Х18Н10Т, предварительно прошедшие аустенизирующий отжиг при температуре $1340 \mathrm{~K}$ в вакууме $10^{-4}$ Па в течение одного часа. Состав исследуемой стали приведен в таблице.

Таблица

Состав стали Х18Н10Т, вес.\%

\begin{tabular}{|c|c|c|c|c|c|c|c|c|c|c|}
\hline $\mathrm{Ni}$ & $\mathrm{Cr}$ & $\mathrm{Mo}$ & $\mathrm{C}$ & $\mathrm{Ti}$ & $\mathrm{Nb}$ & $\mathrm{Si}$ & $\mathrm{V}$ & $\mathrm{P}$ & $\mathrm{S}$ & $\mathrm{Mn}$ \\
\hline 10,8 & 17,9 & - & $0,07-0,1$ & $\begin{array}{r}\geq 5 \mathrm{xC} \\
\text { до } 0,8\end{array}$ & - & 0,74 & - & $\leq 0,025$ & $\leq 0,015$ & 1,75 \\
\hline
\end{tabular}

Исходная структура стали показана на рис. 1. В структуре стали наблюдаются аустенитные зерна с размерами около 30 мкм. Средняя плотность дислокаций составляет $\sim 10^{8} \mathrm{~cm}^{-2}$.

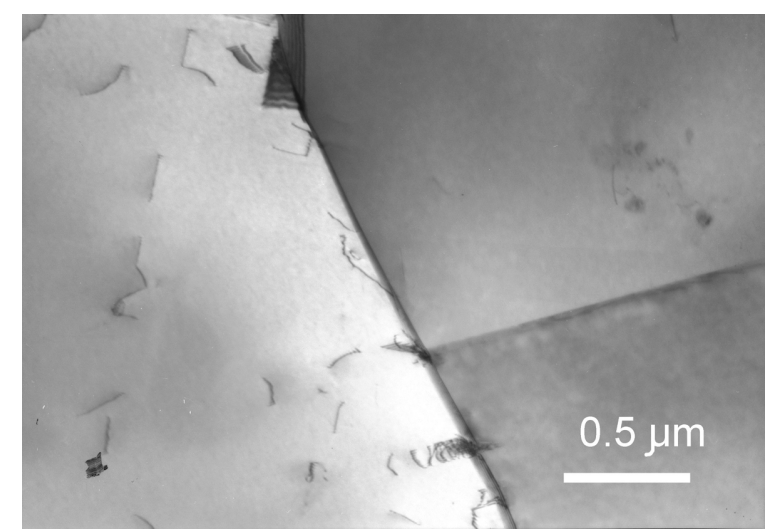

Рис. 1. Исходная структура стали после термической обработки при 1340 K/1 ч

Образцы облучали пучком ионов гелия с энергией 20 кэВ до доз $(1-10) \cdot 10^{20} \mathrm{M}^{-2}$ при комнатной температуре. Температуру облучения контролировали хромель-алюмелевой термопарой. На рис. 2 приведены рассчитанные с помощью программы SRIM 2008 профили распределения пробегов и повреждений ионов гелия с энергией 20 кэВ для дозы облучения $1 \cdot 10^{21} \mathrm{M}^{-2}$. Расчеты проводились с использованием модели Кинчина-Пиза при значении энергии смещения 40 эВ для $\mathrm{Fe}$ и $\mathrm{Cr}$ [7].

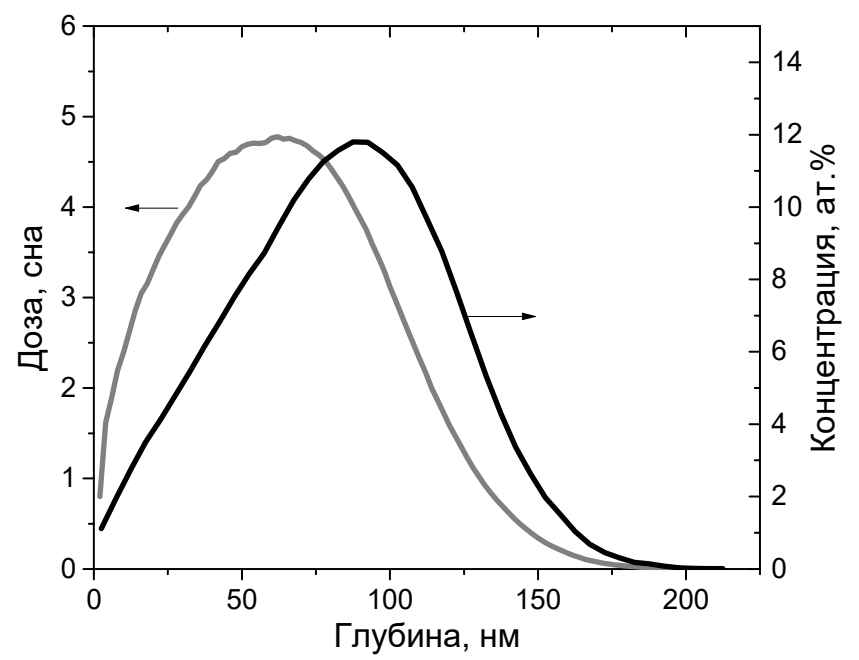

Рис. 2. Профили распределения пробегов (черная кривая) и повреждений (серая кривая) для гелия, имплантированного в сталь с энергией 20 кэВ до дозы $1 \cdot 10^{21} \mathrm{M}^{-2}$

Термоактивированную десорбцию гелия из стали исследовали с помощью присоединенного к экспериментальной камере датчика монопольного радиочастотного масс-спектрометра. Отжиг образцов в интервале температур 300...1600 К выполняли при скорости увеличения температуры $7 \mathrm{Kc}^{-1}$.

Микроструктура имплантированного слоя и морфология поверхности стали на заданных стадиях ТД исследованы с помощью методики «замораживания» состояния образца (прекращение нагрева образца и резкое снижение температуры до комнатной). Изменение микроструктуры облученных образцов исследовали на электронных микроскопах ЭМ-125 и ЈЕМ-2100. Утонение образцов с диаметром 3 мм до толщины, пригодной для исследований в ПЭМ, проводилось стандартной струйной электрополировкой со стороны необлученной 
поверхности. При этом на облученную сторону образца наносился защитный слой лака, предохраняющий ее от растравливания. При появлении в образце отверстия полировка прекращалась. Образец извлекался из тефлонового держателя, промывался в спирте, а затем в ацетоне до растворения защитной лаковой пленки. Окончательная промывка осуществлялась в обезвоженном этиловом спирте. Анализ снимков и построение гистограмм распределения дефектов по размерам выполняли, используя программную обработку изображений.

\section{РЕЗУЛЬТАТЫ И ОБСУЖДЕНИЕ}

С целью определения температурных интервалов выхода гелия из стали были получены спектры его термоактивированной десорбции (рис.3). Сравнение спектров показывает, что температурные интервалы десорбции гелия зависят от дозы облучения. Так при дозе облучения $1 \cdot 10^{20} \mathrm{M}^{-2}$ (расчетная концентрация гелия в максимуме профиля залегания гелия на глубине $\sim 90$ нм составляет $\sim 1,2$ ат.\%) в спектре термодесорбции наблюдается одна хорошо выраженная стадия с максимумом при 1450 К. Точность определения температуры пика составляла $\pm 15 \mathrm{~K}$.

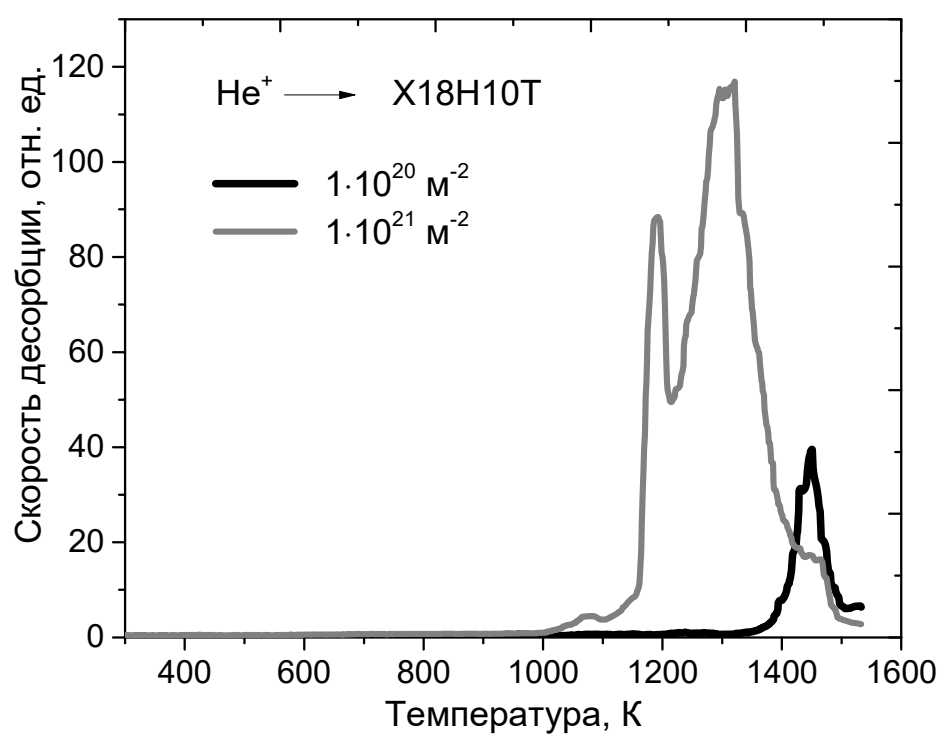

Рис. 3. Спектры термодесорбции гелия из стали, облученной ионами $\mathrm{He}^{+}$при $\mathrm{T}=290 \mathrm{~K}$ до доз $1 \cdot 10^{20}$ и $1 \cdot 10^{21} \mathrm{M}^{-2}$
Увеличение дозы облучения до $1 \cdot 10^{21}$ $\mathrm{M}^{-2}$ (расчетная концентрация гелия в максимуме профиля составляет 12 ат.\%) приводит к уширению температурного интервала газовыделения и смещению начала выхода гелия из образца в область более низких температур. В спектре наблюдаются две группы достаточно хорошо разделенных пиков низкотемпературная $\left(\mathrm{T}_{\text {макс }} \sim 1190 \mathrm{~K}\right)$ и высокотемпературная, состоящая из нескольких перекрывающихся стадий газовыделения. В последнем случае максимум пика, имеющего сложную структуру, приходится на температуру $\sim 1350$ К. Наличие в спектре ТД нескольких разрешаемых пиков указывает на существование нескольких дискретных стадий выделения гелия, отличающихся термодинамическими характеристиками и механизмами выхода Не из стали.

Эволюция микроструктуры стали Х18Н10Т в процессе постимплантационного отжига в интервале

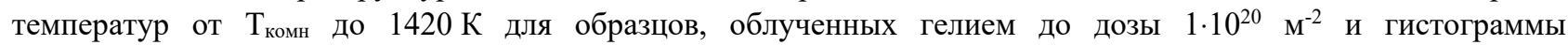
распределения пузырьков по размерам показаны на рис. 4.

Облучение при Ткомн приводит к образованию дефектов дислокационного типа (рис. 4, а). Гелиевые пузырьки при этой температуре не наблюдались. Возможно, их размеры находятся за пределами разрешения микроскопа, составляющего 0,2 нм. Гелиевые пузырьки были зафиксированы только после отжига до температуры 890 К (рис. 4, б). Пузырьки имеют средний размер 0,98 нм, их плотность составляет $3 \cdot 10^{24}$ м $^{-3}$.

Повышение температуры отжига до 1280 К приводит к росту размеров пузырьков до 10 - 15 нм (рис. 4, в). При этом пузырьки, образовавшиеся на границе зерна, имеют размеры, в несколько раз превышающие размеры пузырьков в теле зерна. После отжига до температуры 1420 К средние размеры увеличиваются до 15 - 20 нм (рис. 4, г). Кроме этого наблюдаются полости с размерами до 100 нм, которые могут пересекать поверхность образца. Выход гелия их таких пузырьков обуславливает пик термодесорбции при 1450 К (рис. 3) и появление дырчатой структуры на поверхности образца.

Литературные данные свидетельствуют, что гелий, обладающий наиболее инертной электронной оболочкой, достаточно высокими коэффициентами диффузии и чрезвычайно малой растворимостью в металлах, при введении его в материал ионной имплантацией может вступать в различные реакции с дефектами кристаллической решетки, включая захват и тепловую эмиссию гелия одиночными вакансиями, дивакансиями, а также кластерами больших размеров, поглощение гелия дислокациями, границами зерен и межфазными границами. Также может происходить замещение гелия, находящегося в узлах решетки, собственными междоузельными атомами и радиационное выбивание захваченных атомов гелия в междоузельные положения. Диффундирующие по междоузлиям атомы гелия легко связываются с вакансиями, образуют гелийвакансионные комплексы и пузырьки, и удерживаются в них до высоких температур отжига [6].

Обсуждая эволюцию микроструктуры стали Х18Н10Т после облучения гелием до дозы $1 \cdot 10^{20} \mathrm{M}^{-2}$ и в процессе постимплантационного отжига в интервале температур от Ткомн до 900 К мы можем предположить, что захват гелия на вакансиях или кластерах вакансий в этом температурном интервале достаточно сильный. Атомы гелия теряют свою мобильность, как только они захватываются ловушкой. Вероятно, весь гелий при его 
концентрациях $\sim 1$ ат.\% захватывается в такие комплексы и не участвует в образовании пузырьков. Вследствие этого, влияние гелия на процессы упрочнения аустенитных сталей начинает проявляться при его концентрациях, превышающих 1 ат.\% [5].

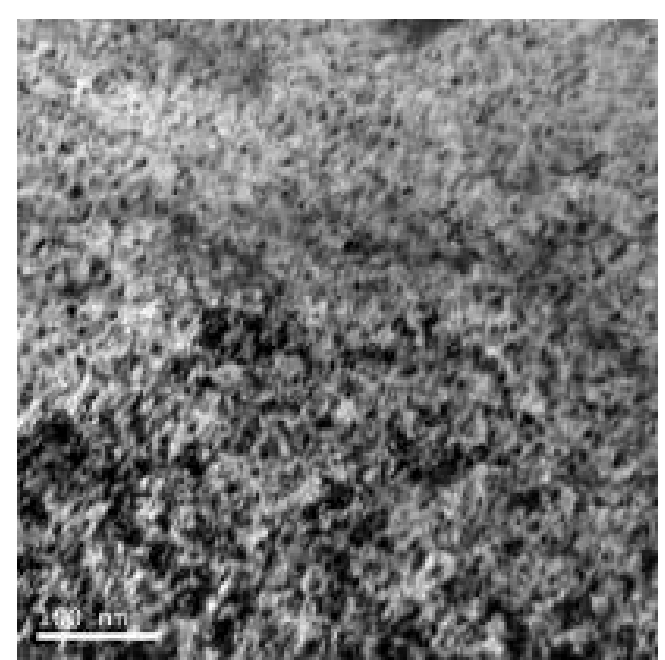

a

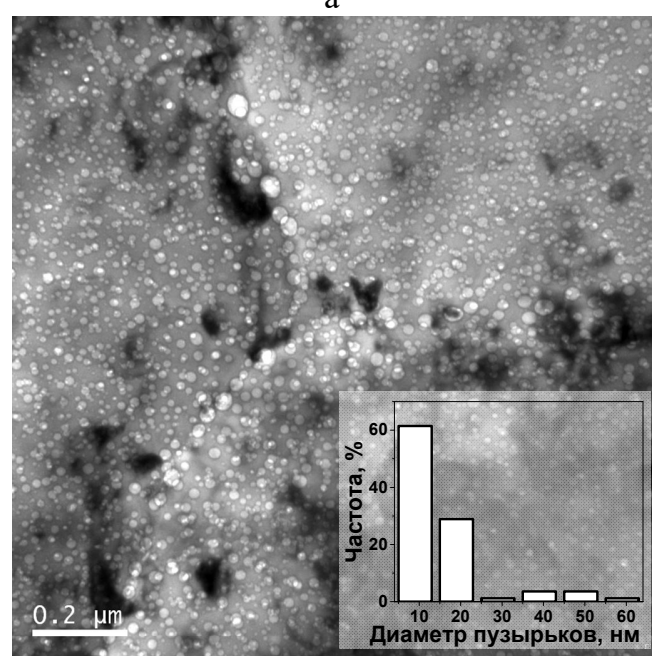

B

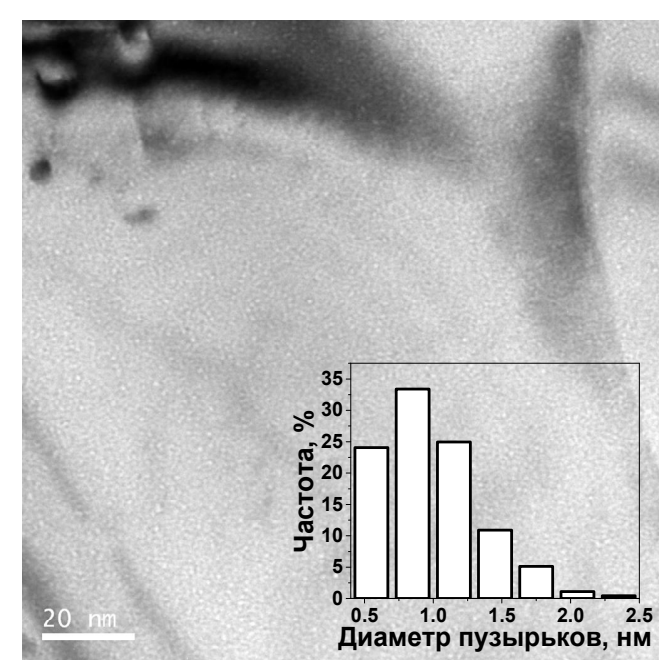

6

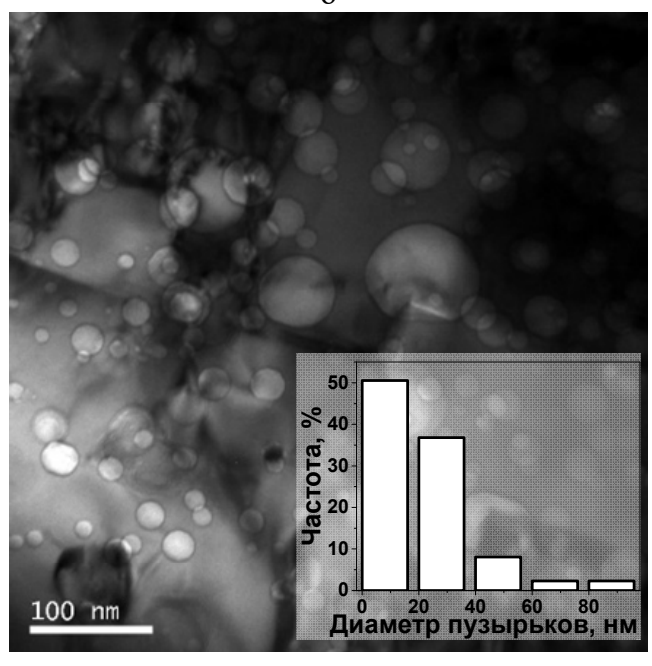

Рис. 4. Микроструктура Х18Н10Т после облучения ионами гелия до дозы $1 \cdot 10^{20} \mathrm{He}^{+} / \mathrm{M}^{2}$ при Ткомн (а) и после отжига при температуре 900 (б), 1280 (в) и 1420 К (г).

Подтверждением вышесказанному являются результаты исследования эволюции микроструктуры стали Х18Н10Т в процессе постимплантационного отжига в интервале температур от Т комн до 1350 К для образцов, облученных гелием до дозы $1 \cdot 10^{21} \mathrm{M}^{-2}$ (рис. 5 и 6).

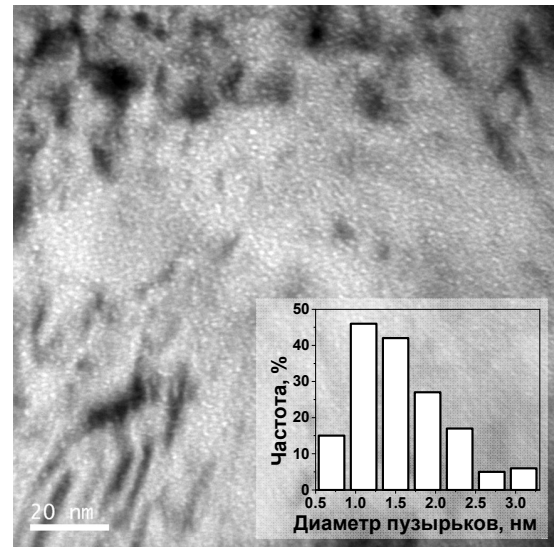

a

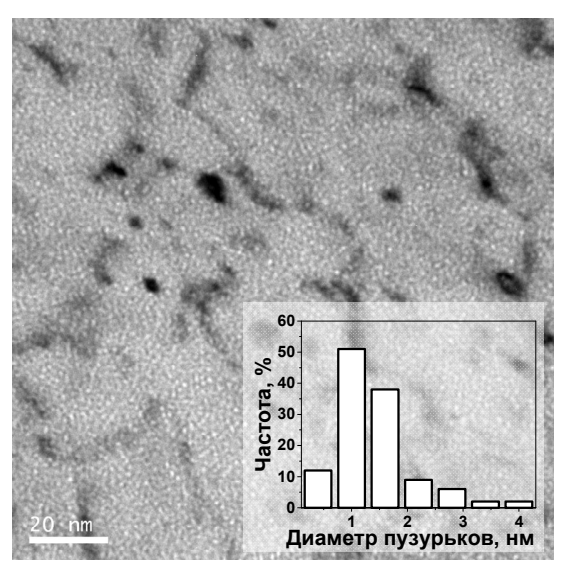

6

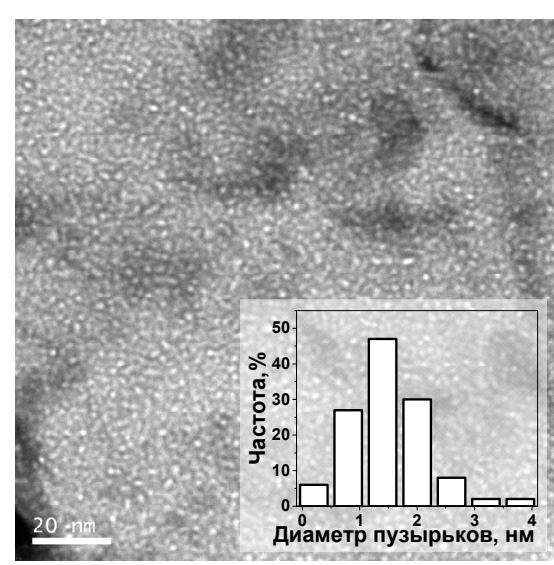

B

Рис. 5. Микроструктура Х18Н10Т после облучения ионами гелия до дозы $1 \cdot 10^{21} \mathrm{He}^{+} / \mathrm{M}^{2}$ при $\mathrm{T}_{\text {комн }}$ (а) и после отжига при температуре 760 (б), 900 К (в) 


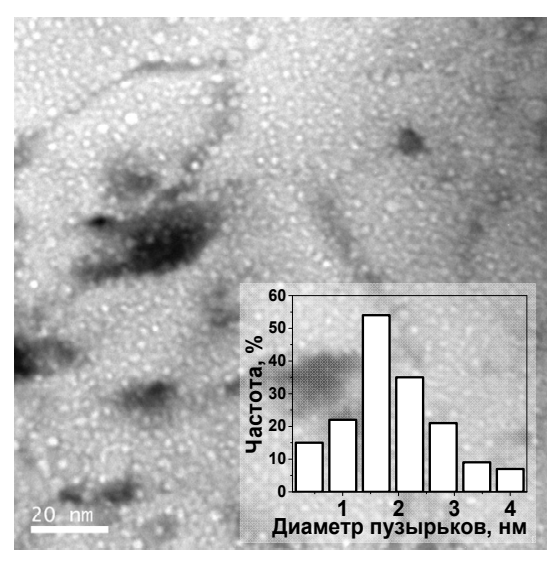

a

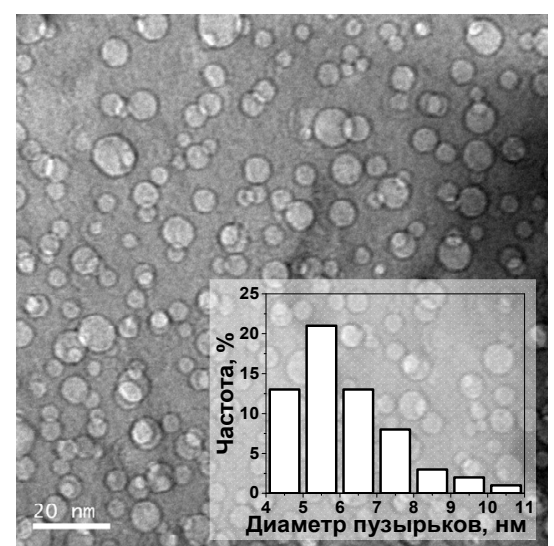

6

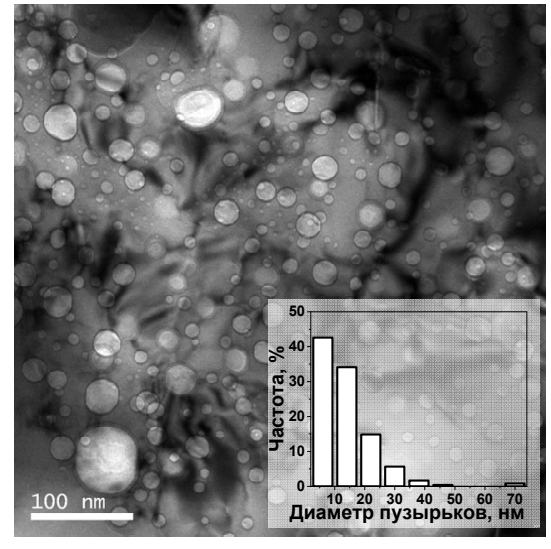

B

Рис. 6. Микроструктура Х18Н10Т после облучения ионами гелия до дозы $1 \cdot 10^{21} \mathrm{He}^{+} / \mathrm{M}^{2}$ при Т комн отжига при температуре 1030 (а), 1200 (б) и 1350 К (в)

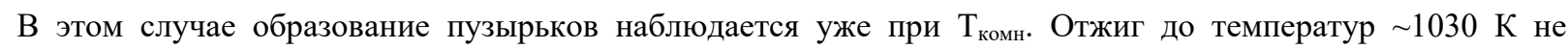
приводит к существенному увеличению их размера. И только после отжига при 1200 К и выше пузырьки начинают укрупняться. Также как и в случае облучения до дозы $1 \cdot 10^{20} \mathrm{He}^{+} / \mathrm{M}^{2}$ размеры некоторых пузырьков достигают сотни нм и они выходят на поверхность (рис. 7).

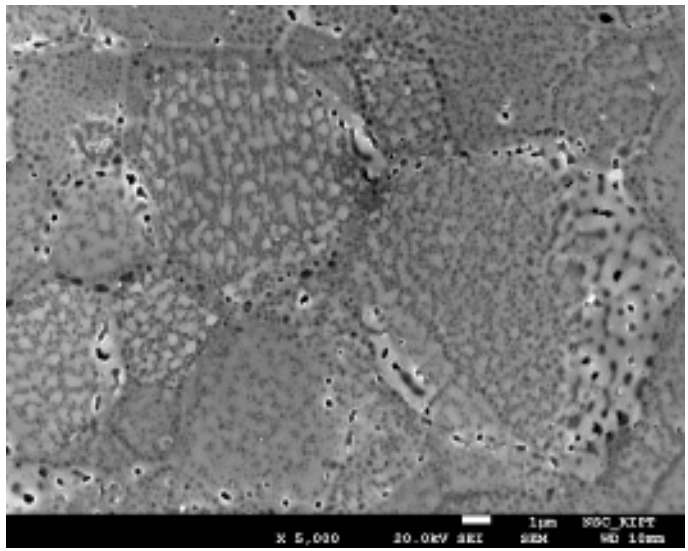

a

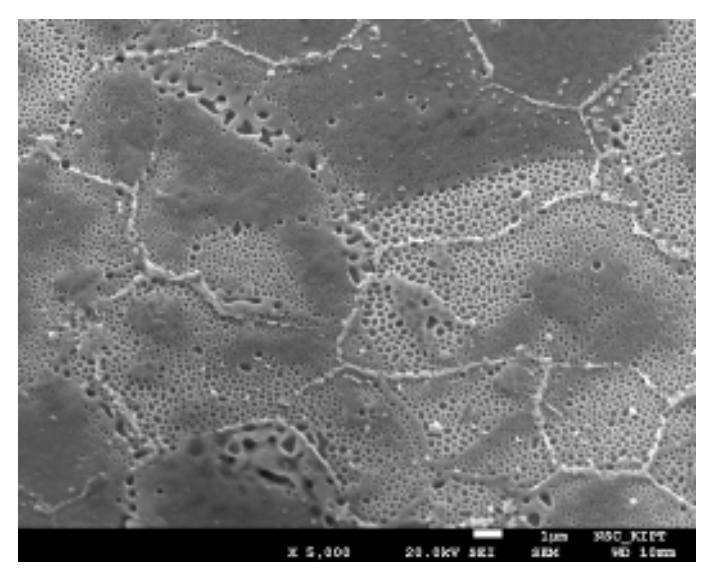

6

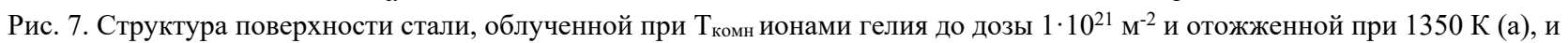
она же после снятия импульсной электрополировкой поверхностного слоя толщиной 20 нм (б)

На поверхности образца помимо дырчатой структуры, обусловленной выходом на поверхность отдельных или нескольких близкорасположенных пузырьков, наблюдается образование каналов из слившихся пузырей (образования белого цвета неправильной формы внутри зерен) (рис. 7, а). После импульсной электрополировки на поверхности видны следы от каналов и дырки от вскрытых пузырей с размерами от 50 до 300 нм (рис. 7, б). Наблюдается неравномерное распределение пузырьков по зерну.

Механизмам роста пузырьков при исследовании гелиевой пористости уделяется большое внимание. Анализ литературных данных показывает, что во время отжига при повышенных температурах небольшие комплексы Не-V, образовавшиеся при низкотемпературном облучении (290-600 К), образуют зародыши пузырьков. Дальнейшее укрупнение зародышей пузырька будут происходить либо путем миграции и коалесценции пузырьков (МК), либо по механизму Оствальда (ОС) - растворение и перезахват [8].

Рост гелиевых пузырьков в результате их миграции и коалесценции убедительно показан в [9]. В экспериментах in situ образцы аустенитного сплава $\mathrm{Fe}-16 \mathrm{Cr}-17 \mathrm{Ni}$ облучали 10 кэВ ионами гелия, используя ионный ускоритель, подключенный к электронному микроскопу. Некоторые образцы, облученные ионами Не ${ }^{+}$, отжигали до температур 970 - 1500 К при этом непрерывно контролировали и регистрировали движение пузырьков на видео. Было установлено, что процессы зарождения пузырьков доминируют при 700 К, тогда как процессы их роста доминируют при температурах выше 900 К. Подвижность гелий-вакансионных комплексов или пузырьков является важным фактором, регулирующим эти процессы. Броуновское движение пузырьков гелия было продемонстрировано и подтверждено наблюдением, что средний квадрат расстояния, на которое мигрируют пузырьки, пропорционален времени. Коэффициент диффузии пузырька зависел от его диаметра и составлял $10^{-18}-10^{-20} \mathrm{M}^{2} / \mathrm{c}$ при 1460 К. В процессе броуновского движения пузырьки коалесцировали и исчезали на поверхности образца. 
В работе [10] с помощью наблюдения "in situ" в просвечивающем электронном микроскопе термоактивированных процессов, протекающих в пленках $\mathrm{Ni}$, облученных ионами Не ${ }^{+}$, и непрерывной их регистрации были зафиксированы оба механизма роста пузырьков. Было показано, что сразу после появления пор их рост происходит за счет диффузии атомов гелия или гелий-вакансионных комплексов различной сложности. Слияние пор практически отсутствует. При повышении температуры, наряду с диффузионным ростом, начинается процесс слияния пор. Проявление этого процесса начинается при температуре $>00$ К. Время одного акта слияния составляет от 0.25 до 0.04 с (предел разрешения аппаратуры). При дальнейшем росте температуры этот процесс проявляется все более отчетливо и, при дозах облучения $2 \cdot 10^{21} \mathrm{M}^{-2}$, приводит к образованию протяженных газонаполненных полостей.

Одновременно с ростом пор наблюдаются процессы аннигиляции: уменьшения диаметра пор вплоть до их полного исчезновения (рис. 8). Наряду с этим происходят процессы роста большой газонаполненной полости за счет перетекания атомов газа из близлежащей поры малого размера. При температуре $>800$ К время последнего процесса составляет порядка 1 с. Обнаружен процесс скачкообразного роста полостей. Доля событий, происходящих по этому механизму, невелика и составляет $2 \ldots 3 \%$ от общего их числа.
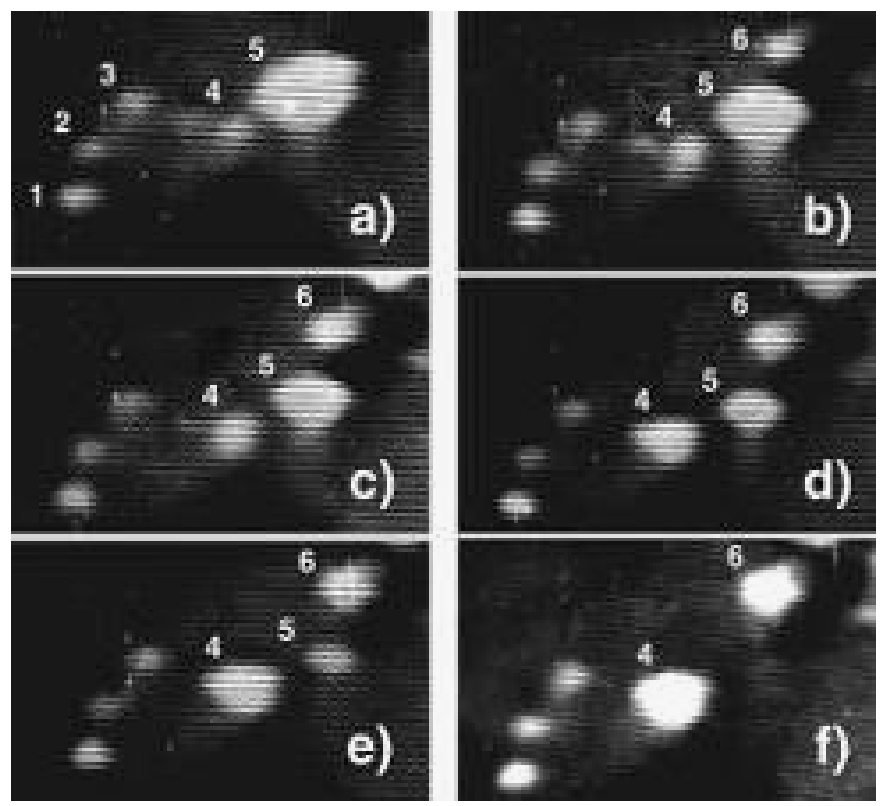

Рис. 8. Микрофотография, иллюстрирующая рост поры 4 за счет объединения с более мелкими окрестными порами, исчезновение поры 5 и синхронный рост поры 6. Поры 1,2,3 не претерпевают изменений [10]

Миграция пузырьков в механизме МК обусловлена процессами перестройки поверхности пузырьков путем, скорее всего, поверхностной диффузии атомов матрицы вблизи пузырька. В этом случае энергия активации процессов, приводящих к изменению плотности пузырьков при отжиге, составляет примерно половину энергии поверхностной диффузии, зависящей от термодинамического состояния пузырьков.

Растворение и перезахват по Оствальду обусловлены термически активированным выходом гелия из малых пузырьков и повторным поглощением их большими пузырьками. В этом случае кажущаяся энергия активации снижения плотности пузырьков, равна энергии диссоциации (выхода) гелия из пузырьков, которая значительно выше энергии поверхностной диффузии. Считается, что механизмы МК и ОС будут доминировать при относительно низких и высоких температурах (и/или высоких и низких концентрациях гелия), соответственно. В дополнение к диссоциации и повторному поглощению атомов гелия, механизм ОС требует диссоциации и повторного поглощения вакансий. Соответственно, этот, в основном, двухкомпонентный механизм, может контролироваться процессом диссоциации атомов гелия или вакансий, в зависимости от того какая из двух энергий диссоциации выше.

Каждому из этих механизмов соответствует определенный тренд зависимости размеров и плотностей пузырьков от температуры отжига. На рис. 9 приведены температурные зависимости средних диаметров и плотностей гелиевых пузырьков для дозы $1 \cdot 10^{21} \mathrm{M}^{-2}$. Экспериментальные данные характеризуются тремя температурными интервалами: 1 - от 300 до 760 К, 2 - от 760 до 1030 К и 3 - от 1030 до 1350 К с явно различающимися трендами.

В низкотемпературной области диаметр и плотность пузырьков практически не меняется. При отжиге в области температур от 760 до 1030 К начинается рост их размеров и снижение плотности. Эта тенденция нарастает в области температур 1030-1350 К. 


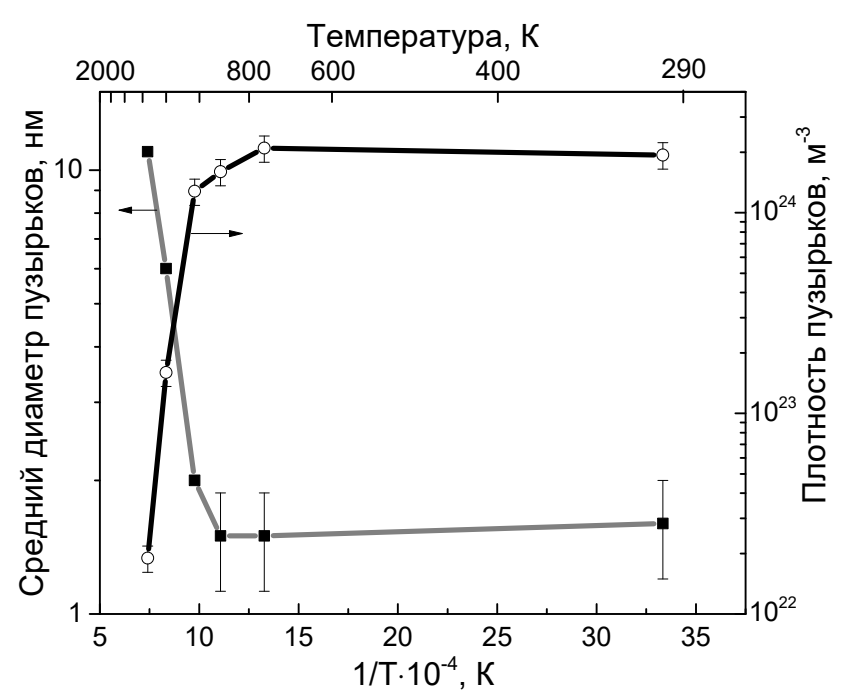

Рис. 9. Температурная зависимость средних диаметров и плотностей гелиевых пузырьков в стали, облученной 20 кэВ-ными ионами гелия до дозы $1 \cdot 10^{21} \mathrm{M}^{-2}$

Оценка энергии активации процесса (тангенс угла наклона высокотемпературной ветви кривой), контролирующего механизм укрупнения гелиевых пузырьков, в этой области дает значение 3,7 эВ. Эта величина хорошо согласуется с теоретически рассчитанной энергией активации $(3,5$ эВ) процесса отрыва атома гелия от микропузырька $\left(\mathrm{E}_{\mathrm{He}}{ }^{\mathrm{diss}}\right)$ по механизму Оствальда [11], а также с экспериментально полученным значением $\mathrm{E}_{\mathrm{He}}{ }^{\text {diss }}$ для высокотемпературной стадии роста пузырьков в стали 304L [12].

\section{ЗАКЛЮЧЕНИЕ}

Исследовано развитие гелиевой пористости при отжиге нержавеющей стали Х18Н10Т, облученной при комнатной температуре ионами гелия с энергией 20 кэВ для одновременного создании смещающих повреждений на уровне 0,5 - 5 сна и концентрации гелия $1-12$ ат.\% .

Установлено, что при концентрации гелия 1 1ат.\% первые видимые пузырьки с диаметром $\sim 1$ нм появляются после отжига до 900 К. При увеличении концентрации гелия до 12 ат.\% пузырьки обнаруживаются при $\mathrm{T}_{\text {комн. }}$

Экспериментальные данные по изменению диаметров и плотности пузырьков в процессе постимплантационного отжига характеризуются тремя температурными стадиями: 1 - от 300 до 760 К, 2 - от 760 до 1030 К и 3 - от 1030 до 1350 К с явно различающимися трендами. На первой - параметры пузырьков не меняются, на второй и третьей стадии изменения имеют градацию от слабого к сильному. Для самой высокотемпературной стадии получено значение 3,7 эВ для энергии активации процессов, контролирующих один из механизмов укрупнения гелиевых пузырьков. Это значение коррелирует с теоретически рассчитанной величиной энергии активации процесса диссоциации $\left(\mathrm{E}_{\mathrm{He}}{ }^{\text {diss }}\right)$ по механизму Оствальда.

\section{S.A. Karpov (D) https://orcid.org/0000-0002-6607-8455}

\section{ORCID IDs}

\section{СПИСОК ЛИТЕРАТУРЫ}

[1]. V.N. Voyevodin, I.M. Neklyudov, Evolution of the structure phase state and radiation resistance of structural materials (Kiev, Naukova Dumka, 2006), P. 374. (in Russian)

[2]. S.J. Zinkle, J.T. Busby, Mater. Today. 12(11), 12 (2009).

[3]. H. Ullmaier, Nucl. Fusion. 24(8), 1039 (1984).

[4]. Y. Dai, G. R. Odette and T.Yamamoto, Comprehensive Nuclear Materials. 1, 141 (2012).

[5]. G.D. Tolstolutskaya, S.A. Karpov, G.Y. Rostova, S. B. Sungurov, G.N. Tolmachova, Вісник ХНУ. Фізика, [Visnyk KhNU. Physics] 23, 66 (2015).

[6]. B. Singh, H. J. Trinkaus, Nucl. Mater. 186, 153 (1992).

[7]. http://www.srim.org/

[8]. H. Trinkaus, B.N. Singh, J. Nucl. Mater. 323, 229 (2003).

[9]. K. Ono, K. Arakawa, M. Oohashi, H. Kurata, K. Hojou, N. Yoshida, J. Nucl. Mater. 283-287, 210 (2000).

[10]. V.I. Bendikov, A.V. Nikitin, V.V. Ruzhytskyi, V.F. Rybalko, S.M. Khazan, PAST. Series: Physics of Radiation Effects and Radiation Materials Science. 1(64), 65 (1996). (in Russian)

[11]. J. Rothaut, H. Schroeder \& H. Ullmaier, Philos. Mag. 47, 781 (1983).

[12]. J. Chen, S. Romanzetti, S.W. Fommer, H. Ullmaier, J. Nucl. Mater. 304, 1 (2002). 